\title{
Quality of life after laparoscopic ventral hernia repair, a prospective observational study
}

\author{
Madasi V. \\ Dr. Venkaiah. Madasi, Assistant Professor, Department of General Surgery, Rajiv Gandhi Institute of Medical Sciences \\ (RIMS), Ongole, Andhra Pradesh,
}

Address for Correspondence: Dr. Venkaiah. Madasi, E-mail: drmadasi@gmail.com

\begin{abstract}
Introduction: Studies on post-operative quality of life in Indian patients undergoing laparoscopic ventral hernia repair are scarce. In recent times, the focus of the surgical outcomes is taking a paradigm shift from traditional and surgeon centered approach of post-operative complications, recurrence rates etc. towards patient centered outcomes like quality of life. Hence the current study has been conducted to assess the quality of life of patients undergoing laparoscopic ventral hernia repair, using Hernia-Related Quality-of-Life Survey (HerQLes) in a tertiary care teaching hospital. Materials \& methods: The study was a prospective observational study, conducted in Rajiv Gandhi institute of medical sciences, a tertiary care teaching hospital in South India on 27 subjects, who underwent ventral hernia repair. Data related to quality of life was collected using a structured and validated instrument, Hernia-Related Quality-of-Life Survey (HerQLes), propsed by Krpata, D. M., et al. Results: The improvement in mean Hernia-Related Quality-of-Life Survey (HerQLes) at 1 week after surgery was only 1.9 ( -8.18 to 11.98 , $\mathrm{P}$ value 0.967$)$, which was statistically significant. When compared to preoperative score, there was 13.50 units increase in mean HerQLes at 1 month (3.41 to 23.58, p value 0.003), and this improvement was 22.60 units (12.51 to 32.68 , p value $<0.001$ ) at 6 months after surgery. The improvement in mean HerQLes at 1 month and 6 months were statistically significant. Conclusions: Laparoscopic ventral hernia repair has led to significant improvement in quality of life at 1 month and 6 months after surgery, when compared with pre-operative quality of life. Even within the post-operative period, there is gradual improvement in quality of life at different follow up periods.
\end{abstract}

Keywords: laparoscopic, ventral hernia, HerQLes.

\section{Introduction}

Incisional hernias and ventral abdominal hernias are defects in the fascia of abdominal wall, are a common occurrence in people undergoing open abdominal surgery [1]. The consequences can range from asymptomatic presence of disease, cosmetic disfigurement to severe consequences like strangulation of herniated bowel segments [2]. But as documented by numerous studies, the negative effect of these hernias on a person's quality of life can be immense [3, 4].

Traditionally open surgical repair has been the mainstay of the treatment for incisional hernia repair [2, 5, 6]. But in last few years, many randomized controlled trials, comparing open and laparoscopic approaches have proposed laparoscopic approach may offer several advantages and may result in better outcomes [7-10]. In recent times, the focus of the surgical outcomes is taking a

Manuscript Received: $5^{\text {th }}$ November 2016

Reviewed: $16^{\text {th }}$ November 2016

Author Corrected:26 $6^{\text {th }}$ November 2016

Accepted for Publication: $11^{\text {th }}$ December 2016 paradigm shift from traditional and surgeon centered approach of post-operative complications, recurrence rates etc $[11,12]$. Increasingly more emphasis is being given to more sophisticated and patient centered outcomes like quality of life $[3,4,13]$. Even though various validated tools are available to assess quality of life in general, the focus again is being shifted towards disease specific quality of life assessment methods. Some of the disease specific quality of life scales like Carolina comfort scale are in use to assess quality of life in patients with hernias in general. [14] A new quality of life scale specific to ventral hernia's has been recently proposed and validated by Krpata, D. M., et al.[3]. Studies on post-operative quality of life in Indian patients undergoing laparoscopic ventral hernia repair are scarce.

\section{Objectives}

To assess the quality of life of patients undergoing laparoscopic ventral hernia repair, using Hernia-Related 
Quality-of-Life Survey (HerQLes) in a tertiary care teaching hospital

\section{Materials \& Methods}

The study was conducted in Rajiv Gandhi institute of medical sciences, a tertiary care teaching hospital in South India. The study was a prospective observational study of 27 subjects, who underwent ventral hernia repair in the study setting, between august 2014 to December 2015, over a 15 month period.

All the study participants were followed up for a period of 6 months, to assess the recurrence rates of the hernia and quality of life following laparoscopic ventral hernia repair (LVHR).

All adult subjects belonging to both genders, who were undergoing surgical repair for the first time were included in the study. Subjects who were undergoing repeat ventral hernia repair were excluded from the study.

Considering the exploratory nature of the study, no formal sample size calculation was done. All the eligible study subjects were recruited into the study consecutively, hence no sampling was done.

As the patients undergoing laparoscopic ventral hernia repair ( LVHR), as part of their routine care were included in the study and no additional intervention was carried out, no ethical approval was sought. Informed written consent was obtained from all the study participants. Confidentiality of the study participants was maintained, as no personal information was disclosed at any point of time during the study.

Data related to quality of life was collected using a structured and validated instrument, Hernia-Related Quality-of-Life Survey (HerQLes), propsed by Krpata, D. M., et al.[3].

The instrument is a 16-question QofL survey tool, constructed and validated by Rasch modeling, fit statistics, person-item mapping, separation index, and reliability in patients undergoing ventral hernia repair.

All the questionnaires were translated into local language by two independent experts and retranslated into English to test for any loss of essence during translation.

The translated version of the questionnaire was administered by the investigator and the responses were documented.

The data was analyzed using mean and standard deviation for quantitative variables, frequency and proportion for categorical variables. The mean Hernia-Related Qualityof-Life Survey (HerQLes), immediately before surgery was compared with the same scores evaluated at 1 week, 1 month and 6 months after surgery. Mean differences in the scores, along with $95 \%$ CI were presented.

Paired t-test was used to test the statistical significance of the differences in the mean scores. IBM SPSS version 21 was used for statistical analysis.

\section{Results}

A total of 27 patients underwent laparoscopic ventral hernia repair.

Table-1: Age and gender distribution of study participants.

\begin{tabular}{|l|c|c|}
\hline Parameter & Frequency & Percentage \\
\hline Age group & 5 & $18.52 \%$ \\
\hline$<40$ & 7 & $25.93 \%$ \\
\hline 40 to 49 & 11 & $40.74 \%$ \\
\hline 50 to 59 & 6 & $22.22 \%$ \\
\hline 60 and above & \multicolumn{3}{|l|}{} \\
\hline Gender & 11 & $40.74 \%$ \\
\hline Male & 16 & $59.26 \%$ \\
\hline Female &
\end{tabular}

The age distribution of the patients shows the most common age group to be between 50 and 59 years, which constituted $40.74 \%$ of the study population. The proportion of subjects between 40 to 49 years was $25.93 \%$. The number of persons less than 40 years were $5(18.52 \%)$ and $6(22.22 \%)$ were aged 60 years or above. (table 1$)$. 
Table-2: Age and gender distribution of study participants.

\begin{tabular}{|l|c|c|}
\hline Parameter & Frequency & percentage \\
\hline Duration in years & 8 & $29.63 \%$ \\
\hline$<1$ year & 6 & $22.22 \%$ \\
\hline 1 to 5 years & 13 & $48.15 \%$ \\
\hline$>$ 5 years & \multicolumn{3}{|l|}{} \\
\hline Grade of hernia & 4 & $14.81 \%$ \\
\hline I & 9 & $33.33 \%$ \\
\hline II & 11 & $40.74 \%$ \\
\hline III & 3 & $11.11 \%$ \\
\hline IV &
\end{tabular}

Majority $(48.15 \%)$ of the study population were having the hernia for more than 5 years. The number of subjects with duration of hernia less than 1 year were $8929.63 \%)$ and the remaining $6(22.22 \%)$ had the hernia between last 1 to 5 years. The most common grade of hernia in the present study was grade III in 11 (40.74\%) subjects. Garde I, II and IV hernia were present in $4(14.81 \%), 9(33.33 \%)$ and $3(11.11 \%)$ subjects respectively. (Table 2)

Table-3: Quality of life as assessed by Hernia-Related Quality-of-Life Survey (HerQLes) in study population.

\begin{tabular}{|c|c|c|c|c|c|}
\hline \multirow{2}{*}{ Timing } & HerQLes & \multirow{2}{*}{$\begin{array}{c}\text { Mean } \pm \text { SD } \\
\text { Mefore Durgery }\end{array}$} & $51.2 \pm 12.3$ & & \multicolumn{2}{|c|}{ 95\% CI of mean difference } & \multirow{2}{*}{ P value } \\
\cline { 4 - 6 } & & & & & \\
\hline (Baseline) & & & & & \\
\hline 1 week & $53.1 \pm 13.5$ & 1.90 & -8.18 & 23.58 & 0.967 \\
\hline 1 month & $64.7 \pm 14.8$ & 13.50 & 3.41 & 32.68 & $<0.001$ \\
\hline 6 months & $73.8 \pm 15.9$ & 22.60 & 12.51 & & 0.98 \\
\hline
\end{tabular}

The improvement in mean Hernia-Related Quality-of-Life Survey (HerQLes) at 1 week after surgery was only 1.9 (-8.18 to 11.98, P value 0.967), which was statistically significant. When compared to preoperative score, there was 13.50 units increase in mean HerQLes at 1 month (3.41 to 23.58, p value 0.003), and this improvement was 22.60 units (12.51 to 32.68, p value $<0.001)$ at 6 months after surgery. The improvement in mean HerQLes at 1 month and 6 months were statistically significant. (Table 3)

Table-4: Improvement in the Hernia-Related Quality-of-Life Survey (HerQLes) score in the post-operative period.

\begin{tabular}{|c|c|c|c|c|c|}
\hline \multirow{2}{*}{ Timing } & \multirow{2}{*}{$\begin{array}{c}\text { HerQLes } \\
\text { Mean } \pm \text { SD }\end{array}$} & \multirow{2}{*}{ Mean Difference } & \multicolumn{2}{|c|}{$95 \%$ CI of mean difference } & \multirow{2}{*}{$P$ value } \\
\hline & & & lower & upper & \\
\hline 1 week (Baseline) & $53.1 \pm 13.5$ & & & & \\
\hline 1 month & $64.7 \pm 14.8$ & 11.60 & 1.51 & 21.68 & 0.017 \\
\hline 6 months & $73.8 \pm 15.9$ & 20.70 & 10.61 & 30.78 & $<0.001$ \\
\hline 1 month (Baseline) & $64.7 \pm 14.8$ & \multirow{2}{*}{9.10} & \multirow{2}{*}{0.98} & \multirow{2}{*}{19.18} & \multirow{2}{*}{0.09} \\
\hline 6 months & $73.8 \pm 15.9$ & & & & \\
\hline
\end{tabular}

When compared to 1 week post-operative mean score, there was statistically significant improvement in the Hernia-Related Quality-of-Life Survey (HerQLes) score at 1 month (11.60, P value 0.017) and at 6 months $(20.70$, P value < 0.001). The improvement in the mean quality of life score between 1 month and at 6 months $(9.10$, p value 0.09$)$ was statistically not significant. (Table 4). 


\section{Discussion}

In many surgical interventions, the focus is being shifted from traditional surgical outcomes to more patient oriented outcomes like quality of life. Few studies in the past have assessed quality of life in pateints undergoing ventral hernia repair. Even though many other studies like studies by Lomanto, D., et al [10]. Sauerland, S., et al.[15] have documented laparoscopic ventral hernia repair may lead to beteer quality of life, as the recurrence rates, selfreported pain and discomfort by patients in various activities of dailiy living was lesser, these studies did not use any validated tool to assess quality of life. Other studies as in study by, Nielsen, K., et al. have done comparative analysis of Dutch and English versions of the Carolinas Comfort Scale (CCS) in subjects with abdominal hernia repairs. The authors have reported significant correlation between the two versions of CCS. The authors also reported, that " $79 \%$ of the patients preferred the CCS to the SF-36, and $83 \%$ considered the CCS a better reflection of their quality of life after hernia repair with mesh.”[14].

There is also a realization that, disease specific quality of life scores may be more appropriate than generalized questionnaires, as the way each disease condition affects quality of life is unique. Considering lack of studies on quality of life improvement following ventral hernia repair, the current study has been conducted on a group of 27 subjects and used newly recommended QOL score by Krpata, D. M., et al.[3] majority of the study population were between between 50 and 59 years and were having the hernia for more than 5 years.

In the current study, no significant improvement was found in HerQLes score 1 week after surgry. But there was 13.50 units increase at 1 month 22.60 units increase at 6 months after surgery in mean HerQLes scores, which was statistically significant. Even when assessing the progress in the post operative period, the mean HerniaRelated Quality-of-Life Survey (HerQLes) score has shown significant progress till 6 months. In their study, Krpata, D. M., et al. have documented a mean pre operative QofL score of 47 and there was significant improvement in abdominal wall function and QofL 6 months after laproscopic ventral hernia repair.[3] Abdalla, R. Z., et al, who have used Carolinas Equation for Quality of Life, to assess quality of life among 21 patients undergoing anterior abdominal wall laparoscopic hernioplasty have reported high satisfaction rates and improvement in quality of life after surgery. The questionnaire was administered through telephonic interview in this study [16]. In study by Criss, C. N., et al, in which quality of life was measured using HerQles survey in 13 patients at the time of each dynamometric analysis, all patients reported an improvement in qualityof-life.[11]

\section{Conclusions}

1. Laparoscopic ventral hernia repair has led to significant improvement in quality of life at 1 month and 6 months after surgery, when compared with pre-operative quality of life

2. Even within the post-operative period, there is gradual improvement in quality of life at different follow up periods.

\section{Limitations}

1. The study tool in the study used Hernia-Related Quality-of-Life Survey (HerQLes), is not yet validated in the local language and on Indian population

2. The sustainability in quality of life, after 6 months was not assessed

\section{Recommendations}

1. There is a need to conducted large scale validation studies on various newly constructed quality of life assessment tools and necessary culture specific local adaptations to be made

2. Long term follow up studies are required to know the sustainability of short term improvements in quality of life.

Conflict of interest: None declared.

Funding: Nil, Permission from IRB: Yes

\section{References}

1. Poelman M, Apers J, van den Brand H, Cense $\mathrm{H}$, Consten E, Deelder J, et al. The INCH-Trial: a multicentre randomized controlled trial comparing the efficacy of conventional open surgery and laparoscopic surgery for incisional hernia repair. BMC surgery. 2013;13:18.

2. Bittner R, Bingener-Casey J, Dietz U, Fabian M, Ferzli GS, Fortelny RH, et al. Guidelines for laparoscopic treatment of ventral and incisional abdominal wall hernias (International Endohernia Society [IEHS])-Part 2. Surgical endoscopy. 2014;28(2):353-79.

3. Krpata DM, Schmotzer BJ, Flocke S, Jin J, Blatnik JA, Ermlich B, et al. Design and initial implementation of HerQLes: a hernia-related quality-of-life survey to assess abdominal wall function. Journal of the American College of Surgeons. 2012;215(5):635-42. 


\section{Research Article}

4. Satterwhite TS, Miri S, Chung C, Spain D, Lorenz HP, Lee GK. Outcomes of complex abdominal herniorrhaphy: experience with 106 cases. Annals of plastic surgery. 2012;68(4):382-8.

5. Bittner R, Bingener-Casey J, Dietz U, Fabian M, Ferzli G, Fortelny R, et al. Guidelines for laparoscopic treatment of ventral and incisional abdominal wall hernias (International Endohernia Society [IEHS])-Part III. Surgical endoscopy. 2014;28(2):380-404.

6. Bittner R, Bingener-Casey J, Dietz U, Fabian M, Ferzli GS, Fortelny RH, et al. Guidelines for laparoscopic treatment of ventral and incisional abdominal wall hernias (International Endohernia Society (IEHS)-part 1. Surgical endoscopy. 2014;28(1):2-29.

7. Awaiz A, Rahman F, Hossain MB, Yunus RM, Khan S, Memon B, et al. Meta-analysis and systematic review of laparoscopic versus open mesh repair for elective incisional hernia. Hernia : the journal of hernias and abdominal wall surgery. 2015;19(3):449-63.

8. Forbes SS, Eskicioglu C, McLeod RS, Okrainec A. Meta-analysis of randomized controlled trials comparing open and laparoscopic ventral and incisional hernia repair with mesh. The British journal of surgery. 2009;96(8):851-8.

9. Fujita T. Re: Meta-analysis of randomized controlled trials comparing open and laparoscopic ventral and incisional hernia repair with mesh. The British journal of surgery. 2009;96(11):1371-2; author reply 2.

10. Lomanto D, Iyer SG, Shabbir A, Cheah WK. Laparoscopic versus open ventral hernia mesh repair: a prospective study. Surgical endoscopy.2006;20(7):1030-5.
11. Criss CN, Petro CC, Krpata DM, Seafler CM, Lai N, Fiutem J, et al. Functional abdominal wall reconstruction improves core physiology and quality-of-life. Surgery. 2014;156(1):176-82.

12. Eriksen JR. Pain and convalescence following laparoscopic ventral hernia repair. Danish medical bulletin. 2011;58(12):B4369.

13. Tollens $\mathrm{T}$, Topal H, Lucardie A, Vermeiren $\mathrm{K}$, Aelvoet C. Long-term Outcome on the use of the Ventralight ST Hernia Patch in Laparoscopic Ventral Hernia Repair. Surgical technology international. 2015;26:157-61.

14. Nielsen K, Poelman MM, den Bakker FM, van der Ploeg T, Bonjer HJ, Schreurs WH. Comparison of the Dutch and English versions of the Carolinas Comfort Scale: a specific quality-of-life questionnaire for abdominal hernia repairs with mesh. Hernia : the journal of hernias and abdominal wall surgery. 2014;18(4): 459-64.

15. Sauerland S, Walgenbach M, Habermalz B, Seiler CM, Miserez M. Laparoscopic versus open surgical techniques for ventral or incisional hernia repair. The Cochrane database of systematic reviews. 2011 (3):Cd007781.

16. Abdalla RZ, Garcia RB, Said DF, Abdalla BMZ. QUALITY OF LIFE OF IN PATIENTS SUBMITTED TO ANTERIOR ABDOMINAL WALL LAPAROSCOPIC HERNIOPLASTY. Arquivos Brasileiros de Cirurgia Digestiva : $\mathrm{ABCD}=$ Brazilian Archives of Digestive Surgery. 2014;27(1):30-3.

\section{How to cite this article?}

Madasi V. Quality of life after laparoscopic ventral hernia repair, a prospective observational study. Int J surg Orthopedics 2016;2(4):55-59.doi:10.17511/ijoso.2016.i4.01. 